\title{
Electric Field Effects on One-Bond Indirect Spin-Spin Coupling Constants and Possible Biomolecular Perspectives (Supporting Information)
}

Aleksandr B. Sahakyan*, Aleksan G. Shahkhatuni, Astghik A. Shahkhatuni and Henry A. Panosyan Molecule Structure Research Center of National Academy of Sciences, Yerevan 0014, Armenia.

aleksahak@msrc.am

TABLE S1: The angular dependence of the ${ }^{1} \mathrm{~J}_{\mathrm{CH}}$ and ${ }^{1} \mathrm{~J}_{\mathrm{NH}}$ couplings in methylamine accompanied with the same angular dependences for the corresponding $\mathrm{F}_{\mathrm{CH}}{ }^{0}$ and $\mathrm{F}_{\mathrm{NH}}{ }^{0}$ internal field projections along the $\mathrm{C}-\mathrm{H}$ and $\mathrm{N}-\mathrm{H}$ bonds and acting at carbon and nitrogen atoms respectively. The $\Delta \Phi=0$ dihedral angle corresponds to the antiperilanar arrangement of the $\mathrm{C}-\mathrm{H}$ bond and the nitrogen lone electron pair.

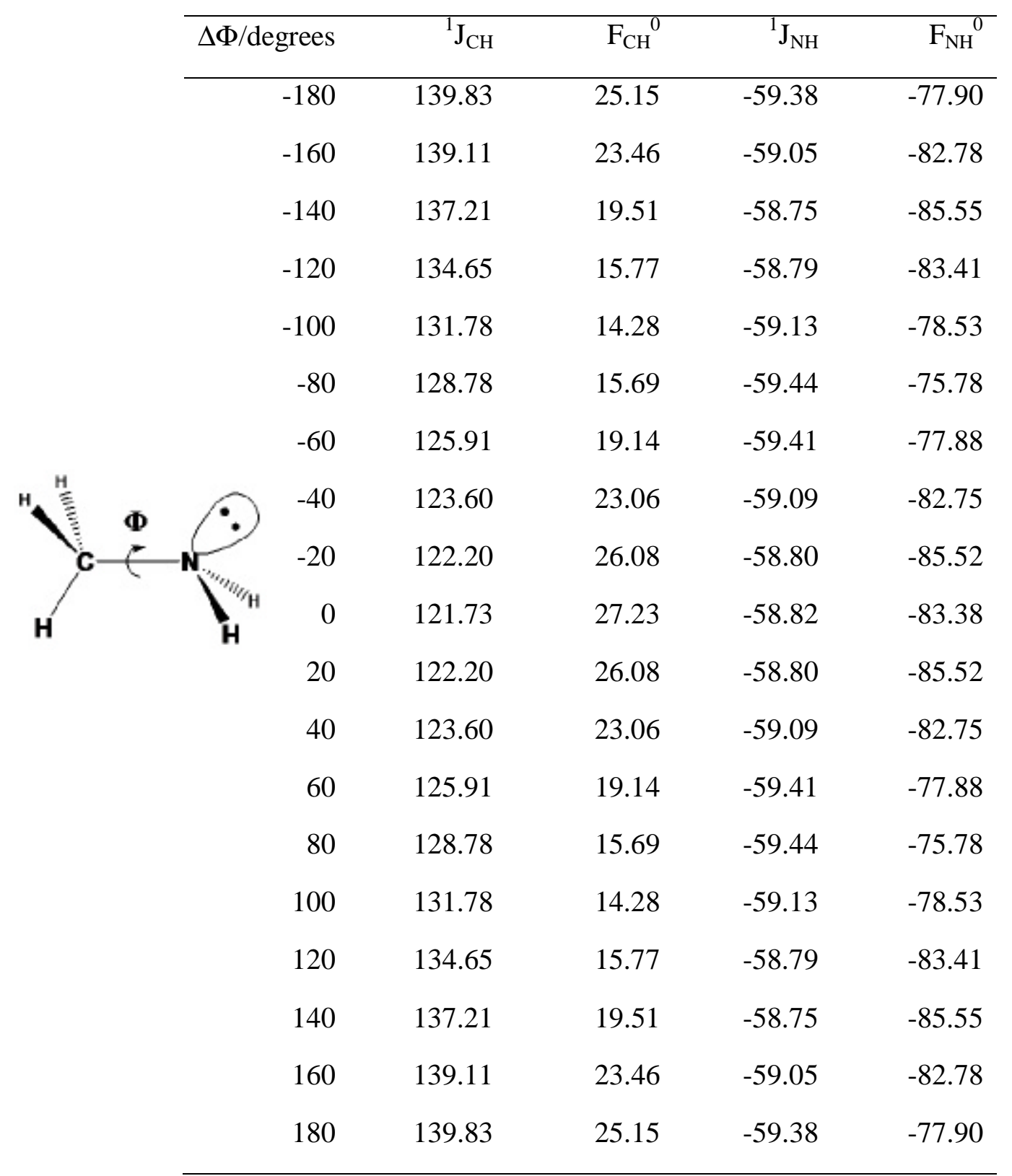


TABLE S2: Nitrogen pyramidality effects on the ${ }^{1} \mathrm{~J}_{\mathrm{NH}}$ coupling and the $\mathrm{F}_{\mathrm{NH}}{ }^{0}$ internal field values. The $\Delta \varphi=0$ corresponds to the optimized structure of ammonia.

\begin{tabular}{rrr}
\hline$\Delta \varphi /$ degrees & ${ }^{1} \mathrm{~J}_{\mathrm{NH}}$ & $\mathrm{F}_{\mathrm{NH}}{ }^{0}$ \\
\hline-18 & -93.34 & -5.86 \\
-15 & -88.62 & -14.58 \\
-10 & -77.78 & -35.87 \\
-8 & -72.95 & -46.03 \\
-6 & -68.07 & -56.73 \\
-4 & -63.28 & -67.76 \\
-2 & -58.67 & -78.88 \\
0 & -54.31 & -89.92 \\
2 & -50.25 & -100.73 \\
4 & -46.50 & -111.19 \\
6 & -43.07 & -121.16 \\
8 & -39.95 & -130.48 \\
10 & -37.13 & -138.97 \\
14 & -32.27 & -152.92 \\
17 & -29.18 & -161.40 \\
\hline & &
\end{tabular}

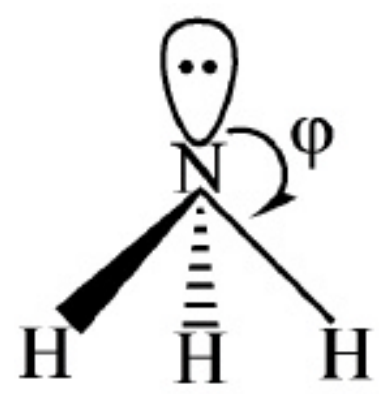


TABLE S3: The change in the ${ }^{1} \mathrm{~J}_{\mathrm{NH}}$ couplings and $\mathrm{F}_{\mathrm{NH}}{ }^{0}$ internal field values against the rotation along the $\mathrm{C}-\mathrm{N}$ bond in formamide molecule with the rest of the structure optimized at each point. The $\theta=0$ angle corresponds to the syn arrangement of the $\mathrm{N}-\mathrm{H}$ bond.

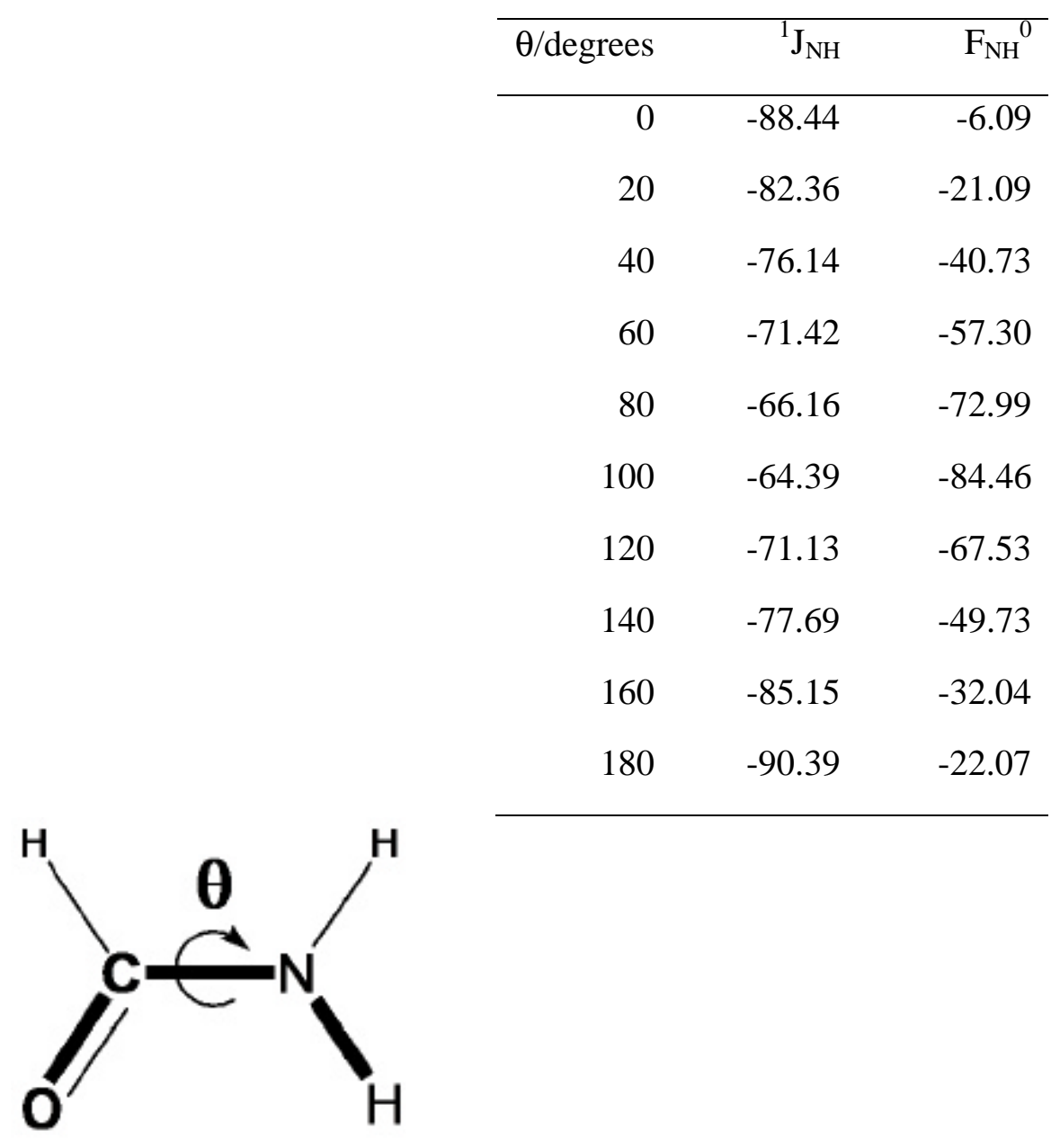

